Georgia State University

ScholarWorks @ Georgia State University

$6-15-2018$

\title{
The Good, the Bad, and the Indifferent: Physical Disability, Social Role Configurations, and Changes in Loneliness Among Married and Unmarried Older Adults
}

\author{
David F. Warner \\ University of Nebraska - Lincoln, dwarner3@unl.edu \\ Scott Adams \\ University of Nebraska - Lincoln, scott.adams@huskers.unl.edu \\ Raeda Anderson \\ Georgia State University, randerson39@gsu.edu
}

Follow this and additional works at: https://scholarworks.gsu.edu/univ_lib_facpub

Part of the Family, Life Course, and Society Commons

\section{Recommended Citation}

Warner, David F., Scott A. Adams, and Raeda K. Anderson. (2018). "The Good, the Bad, and the Indifferent: Physical Disability, Social Role Configurations, and Changes in Loneliness Among Married and Unmarried Older Adults." Journal of Aging and Health doi: 10.1177/0898264318781129.

This Article is brought to you for free and open access by the Georgia State University Library at ScholarWorks @ Georgia State University. It has been accepted for inclusion in University Library Faculty Publications by an authorized administrator of ScholarWorks @ Georgia State University. For more information, please contact scholarworks@gsu.edu. 
The Good, the Bad, and the Indifferent: Physical Disability, Social Role Configurations, and Changes in Loneliness Among Married and Unmarried Older Adults
Journal of Aging and Health

$|-3|$

(C) The Author(s) 2018

Reprints and permissions: sagepub.com/journalsPermissions.nav DOI: 10.1 I77/08982643/878| I29 journals.sagepub.com/home/jah

(SAGE

\author{
David F. Warner, PhD ${ }^{1,2}$ iD, \\ Scott A. Adams, PhD', \\ and Raeda K. Anderson, PhD'
}

\begin{abstract}
Objectives: To examine how social role configurations (SRCs) combinations of the quality of spousal, family, and friend relationshipsmoderate the association between functional limitations (FLs) and loneliness among married and unmarried older adults and whether this differs by gender. Method: Longitudinal data from the National Social Life, Health, and Aging Project on married $(n=945)$ and unmarried $(n=443)$ older adults (aged 57-85 years). Latent class analysis was used to identify SRCs. Tobit regression models examined the associations between FLs, SRCs, and loneliness. Results: Nine SRCs were identified. The effectiveness of SRCs for coping with FLs did not differ by marital status despite higher loneliness among the unmarried. Only for women with FLs did SRCs characterized by negativity/strain exacerbate loneliness. For men with FLs, SRCs characterized
\end{abstract}

\footnotetext{
'University of Nebraska-Lincoln, NE, USA

${ }^{2}$ Bowling Green State University, OH, USA

Corresponding Author:

David F. Warner, Associate Professor, Department of Sociology, University of

Nebraska-Lincoln, 7I I Oldfather Hall, Lincoln, NE 68588, USA.

Email: david.f.warner@gmail.com
} 
by excess positivity/support were problematic. Discussion: These findings underscore the importance of considering how SRCs provide resources for coping with FLs that have gendered implications.

\section{Keywords}

disability, social support, stress process, family life course, gender

Physical disability can threaten older adults' social well-being, including their feelings of loneliness (Korporaal, van Groenou, \& van Tilburg, 2008). Loneliness is an important public health measure because it predicts declines in self-rated health and cognition, health services use (Cacioppo, Hawkley, \& Berntson, 2003), and even mortality (Holt-Lunstad, Smith, Baker, Harris, \& Stephenson, 2015). Yet, how disablement leads to loneliness may depend on the quality of one's social relations as supportive ties can serve as coping resources that may render stressors less threatening (Thoits, 1995). Indeed, prior studies show that marital quality is key for loneliness among older adults with functional limitations (Warner \& Adams, 2016; Warner \& KelleyMoore, 2012). Less is known, however, about how unmarried adults' social relations affect loneliness and how this compares to married older adults. This is a notable gap given that unmarried older adults are particularly at risk of functional limitations (Hughes \& Waite, 2009; Kail, 2015) and a growing number of older adults are never married or divorced (Lin \& Brown, 2012). The increasing number of unmarried older adults may especially place older men at risk given that their social ties are more bound by marriage (Antonucci \& Akiyama, 1987; Birditt \& Antonucci, 2007). Thus, there is a critical need to examine how the quality of unmarried older adults' social relations affect their ability to cope with functional limitations and how these processes compare with those among the married.

A challenge of such comparisons, however, is that older adults' social ties are comprised of both positive/supportive and negative/straining aspects across multiple roles: with spouses, with family, ${ }^{1}$ and with friends (Akiyama, Antonucci, Takahashi, \& Langfahl, 2003). Relations across these multiple roles thus have the potential to combine in several different ways (Birditt \& Antonucci, 2007). We capture this multidimensionality by classifying individuals into discrete social role configurations (SRCs) based on their assessments of how positive/supportive and negative/strained their relations are with spouses (if married), family, and friends (Miche, Huxhold, \& Stevens, 2013). Consequently, drawing on the stress process and family life course perspectives (Macmillan \& Copher, 2005; Pearlin \& Bierman, 2013), we use 
latent class analysis (LCA) and nationally representative longitudinal data from the National Social Life, Health, and Aging Project (NSHAP; Waite et al., 2014) to advance the understanding of how different latent SRCs affect the association between functional limitations and changes in loneliness among both married and unmarried older adults, giving particular attention to gender differences in these processes.

\section{Background}

\section{The Social Relations of Married and Unmarried Older Adults}

Older adults are embedded in a web of social relations (Antonucci \& Akiyama, 1987). Each relation encompasses both the social role with its attendant behavioral expectations based on widely held cultural schema (e.g., spouse) and subjective evaluations derived from past interactions evaluated against those normative expectations (e.g., marital quality). Understanding how multiple social roles operate together requires "recognition that the meaning of any given role is dependent upon the presence or absence of other roles" (Macmillan \& Copher, 2005, p. 859). Older adults' social relations are arranged hierarchically based on these expectations (Antonucci, Fiori, Birditt, \& Jackey, 2010), decreasing in importance from one's spouse to family to friends (Chen \& Feeley, 2014; Waite \& Harrison, 1992).

The primacy of the spouse reflects the fact that marriage organizes other family and nonfamily ties (Antonucci \& Akiyama, 1987; Kalmijn, 2003; Waite \& Lehrer, 2003). Moreover, marriage is "greedy" in that the prioritization of the spousal relationship leads to less frequent contact and exchange with other family and friends (Sarkisian \& Gerstel, 2016). One's spouse is expected to be the primary source of companionship, emotional support, and physical care (Cutrona, 1996; Spitze \& Ward, 2000).

For unmarried older adults, family and friends substitute for a spouse in the social relations hierarchy (Connidis \& Davies, 1992; Johnson, 1983; Shanas, 1979). For example, in a study of German adults aged 53 to 79 years, Pinquart (2003) found that family and friends were more effective at reducing loneliness among the unmarried than the married. Although friends appear more important than family for companionship (Pinquart \& Sorensen, 2001), family are preferred for more demanding forms of support (Curran, McLanahan, \& Knab, 2003). Thus, in the absence of marriage, other ties gain importance in the ways consistent with their role expectations (Antonucci et al., 2010).

Yet, even as they gain importance, unmarried older adults' ties with family and, especially, friends are more contingent — requiring more active engagement 
to maintain - than relationships with spouses. Family and friend relations do not possess the same kind of well-defined expectations as the spousal role. Absent such norms, support derives from reciprocal exchanges over time (Plickert, Côté, \& Wellman, 2007). Yet, unmarried older adults have less frequent social interaction with family (Barrett, 1999; Pinquart, 2003) and lower perceptions of support (Curran et al., 2003; Stokes \& Moorman, 2017; Thoits, 1995) than do the married. Relationships with friends, however, follow the expected pattern of more frequent (Kalmijn, 2012; Waite \& Harrison, 1992) and higher quality interactions (Pinquart, 2003), with more reciprocal exchange (Liebler \& Sandefur, 2002).

These differences in contact notwithstanding, perceptions of support are only moderately correlated with interaction with social ties (Cornwell \& Waite, 2009; Due, Holstein, Lund, Modvig, \& Avlund, 1999). Rather, it appears that the normative expectations about social roles are key. Accordingly, unmarried older adults consistently report worse psychosocial well-being, such as more depressive symptoms, lower life satisfaction, and greater loneliness (e.g., Lee \& Szinovacz, 2016; Pinquart, 2003; Stokes \& Moorman, 2017). The more contingent nature of unmarried persons' relationships with friends and, to a lesser extent, family thus creates potential vulnerabilities for their ability to cope with health-related stressors, such as physical disability.

\section{Disablement, Social Relations, and Loneliness in the Stress Process}

The stress process perspective (Pearlin \& Bierman, 2013) highlights the potential of social relations to act as coping resources, helping to alleviate feelings of isolation that may result when functional limitations undermine one's ability to engage in desired social activities (Korporaal et al., 2008). Yet, the ability of a social relation to moderate the effect of a health-related stressor depends on the quality of that relation - how positive/supportive or negative/strained it is - rather than its mere presence. Indeed, prior studies consistently show that perceived support is more strongly associated with better health and well-being than the number of ties one possesses or even actual receipt of support (e.g., Merz, Schuengel, \& Schulze, 2009).

Older adults may have especially high expectations of support from their social relations because as individuals age, they pursue and maintain social ties that they find more rewarding (Carstensen, Fung, \& Charles, 2003). Although close relationships - especially, with spouses or family - are more likely to be characterized by both positive and negative emotions simultaneously (Fingerman, Hay, \& Birditt, 2004; Lee \& Szinovacz, 2016), this 
selectivity results in social relations that are less negative/straining with age (Akiyama et al., 2003; Birditt \& Antonucci, 2007). Thus, when social relations fail to meet those expectations and/or are overly negative ("strained"), this may be particularly distressing for older adults (Chen \& Feeley, 2014). Indeed, Hawkley and Kocherginsky (2018) show that low family support and strained friendships are both associated with increased loneliness over time.

Differences in how positive and negative aspects of social relations combine and operate simultaneously help to explain why marriage does not automatically protect one from loneliness (Hawkley \& Kocherginsky, 2018; Russell, 2009). Rather, it is an individual's complete assessment of his or her marriage as emotionally positive and/or negative that matters (Burman \& Margolin, 1992). Consistent with the stress process perspective's stress-buffering hypothesis, functionally limited older adults with higher levels of marital closeness and positive marital quality have lower levels of depression, anxiety, and loneliness (Mancini \& Bonanno, 2006; Warner \& Kelley-Moore, 2012). Higher levels of negative marital quality, conversely, are associated with adverse effects over time, including having more health problems (Walen \& Lachman, 2000) and exacerbating depressive symptoms among functionally limited older adults (Bookwala \& Franks, 2005). Overall, a low quality marriage - independent of functional status - is associated with worse mental and physical health (Hawkins \& Booth, 2005; Stokes \& Moorman, 2017).

The primacy of the marital relationship, however, may mean that older adults with unsupportive spouses or who are unhappily married are limited in their ability to compensate for this deficit by drawing on support from other social relations. For example, Warner and Adams (2012) found that a low quality marriage was associated with elevated loneliness and, because the marital relationship is most proximate, supportive relations with (nonspouse) family and friends did not compensate for a problematic marriage (but see Birditt \& Antonucci, 2007).

Although prior research generally shows health-compromising effects, some studies suggest, paradoxically, that ostensibly negative behaviors can be beneficial when they occur in the context of an otherwise supportive relationship. Rather than reflecting ambivalence, negative behaviors such as making demands or offering criticism that occur in combination with supportive exchanges signal relationship investment and/or caregiving (Birditt \& Antonucci, 2008; Warner \& Adams, 2016). Support, moreover, may have harmful effects - such as depression-when it is overly solicitous (e.g., Reinhardt, Boerner, \& Horowitz, 2006).

The foregoing discussion suggests that for married older adults, the relative balance of positive to negative aspects of the marital relationship may 
have implications for coping with health-related stressors such as physical disability. However, as a family life course perspective reminds us (Macmillan $\&$ Copher, 2005), the quality of each of older adults' social relations is contingent on another and must be considered simultaneously.

Thus, when positive and negative marital quality are combined with differences in support and strain from family and friends, this creates the potential for heterogeneity in older adults' SRCs. It is reasonable to expect similar SRC heterogeneity among unmarried persons - especially, as family substitutes for a spouse (Connidis \& Davies, 1992; Ha, 2008; Shanas, 1979). There has been only limited attention, however, to understanding the quality of unmarried older adults' social relations (and, especially, how they compare with the married). Nonetheless, there is some evidence of parallel processes with, for example, excessive support to unmarried older adults leading to decreased positive mood (Silverstein, Chen, \& Heller, 1996). Whether unmarried older adults with supportive SRCs fare just as well as married older adults is not clear from prior studies as explicit comparisons of the quality and consequences of social relations by marital status are lacking. Prior studies do show, however, that the unmarried face persistent unmet social needs, such as the lack of a confidant (e.g., Barrett, 1999). This suggests that for the unmarried, family and friends may be less effective in offering support in the face of health-related stressors than spouses are for the married.

\section{The Gendered Context of Social Relations}

Understanding the ability of SRCs to buffer the loneliness-inducing effects of disablement requires consideration of how these processes may differ by gender (Macmillan \& Copher, 2005). Studies of married persons have long focused on the potential for husbands to benefit more from marriage than wives (Bernard, 1972; Nock, 1998), but gendered role expectations are not simply limited to marriage. Older men and women in contemporary cohorts were socialized according to distinct cultural norms pertaining to their social lives across the adult life course. Masculine norms centered on self-reliance and authority in social interactions, whereas feminine norms stressed interdependence and emotional responsiveness (Neff \& Karney, 2005).

Directly relevant to the current article is the fact that these gendered social structures led to different family norms, with women primarily responsible for maintaining contact with family members and friends (Waite \& Harrison, 1992). Thus, men tend to have low levels of emotional exchange with social ties, whereas women engage in high levels of emotional support (Curran et al., 2003; Liebler \& Sandefur, 2002). Men also have friendship networks 
that are smaller and comprised of shorter-duration ties than women (Miche et al., 2013). Given their closer family ties (Silverstein \& Bengtson, 1997) and larger friend networks (Miche et al., 2013), women have both more supportive and more straining relationships than men (Fingerman et al., 2004; Lee \& Szinovacz, 2016).

Prior studies examining gender differences in how social relations affect psychosocial outcomes for married disabled older adults have produced mixed results. Some, largely cross-sectional, studies suggest social relations operate similarly for married men and women (Ryan, Wan, \& Smith, 2014; Warner \& Kelley-Moore, 2012). In contrast, longitudinal research suggests that social relations are differentially associated with changes in well-being for men and women - where demands from social relations benefit men with functional limitations but are detrimental for women (Warner \& Adams, 2016). Women's greater investment in and emotional exchange with family and friends (Salari \& Zhang, 2006) mean that they experience negative interactions more frequently than men (Birditt \& Antonucci, 2007). Accordingly, such negative behaviors may feel routine to older women and therefore do little to amplify the effect of disablement on loneliness.

Given the gendered nature of marital roles, married men tend to have fewer ties to family and friends than women do. Consequently, men depend more on marriage for support, companionship (Antonucci \& Akiyama, 1987; Kalmijn, 2003; Silverstein \& Bengtson, 1997), and caregiving (Spitze \& Ward, 2000). Women, however, rely less on a spouse for socioemotional fulfillment and are more likely to report stronger perceptions of negative spousal behaviors even in instances when the spouse is supportive (Neff \& Karney, 2005). The centrality of marriage for men's social connections suggests that unmarried men may be particularly vulnerable to social isolation (Nock, 1998). Indeed, unmarried men have fewer ties, have less supportive relationships, and are lonelier than unmarried women (Barrett, 1999; Curran et al., 2003; Pinquart, 2003) even as they interact more frequently with friends than do married men (Sarkisian \& Gerstel, 2016). Overall, marriage is key for men's psychological well-being, whereas there is less marital status differentiation among women.

\section{Current Study}

Guided by the stress process and family life course perspectives (Macmillan \& Copher, 2005; Pearlin \& Bierman, 2013), the current study has three primary aims. First, we examine how different SRCs for both married and unmarried older adults are associated with loneliness. These configurations 
reflect how the positive/supportive and negative/strained aspects of relationships with a spouse, family, and friends combined may be classified as distinct latent classes. Second, we consider whether these SRCs moderate the effect of functional limitations on loneliness for married and unmarried older adults. Third, we explore whether the moderating effects of SRCs differ for men and women.

\section{Data and Method}

Data were from Waves 1 and 2 of the NSHAP (Waite et al., 2014), a nationally representative panel of 3,005 community-dwelling adults aged 57 to 85 years in the contiguous United States. Respondents were interviewed in $2005 / 2006$ and again in 2010/2011. Roughly $75 \%$ of Wave 1 respondents provided a Wave 2 interview $(N=2,261) ; 4.63 \%(n=139)$ were too ill to be re-interviewed, $14.31 \%$ had died $(n=430)$, and 5.82\% $(n=175)$ otherwise attrited. Data on physical health, mental health, and social relations were collected during 2-hour in-home interviews. To minimize respondent burden, NSHAP used a modularized design so that some questions were included in a Leave Behind Questionnaire (LBQ). In total, $84 \%$ of respondents returned the LBQ at Wave 1 and $88 \%$ returned it at Wave 2 .

\section{Analytic Sample}

We restricted our sample of respondents interviewed at both waves to those with (a) the same marital status, excluding 278 (12.3\%) respondents who experienced a marital change, (b) LBQs at both waves as our dependent variable was measured in the LBQ, excluding 401 respondents (20.2\%), (c) complete information on loneliness at both waves, excluding 186 (11.8\%) respondents, and (d) complete information on functional limitations and all other variables, excluding an additional $5(0.4 \%)$ respondents. Our final analytic sample was 1,388 older adults, two thirds of whom were married $(n=$ $945)$ and one third of whom were unmarried $(n=443)$. We combined cohabiting respondents with the married as there were too few to analyze separately $(n=24)$.

Compared with all Wave 1 respondents, our analytic sample was younger, slightly better educated, less likely to be Black, and had slightly less negative relationships (not shown). In preliminary analyses, we assessed the implications of nonrandom attrition using inverse probability weighting as recommended by Hawkley, Kocherginsky, Wong, Kim, and Cagney (2014), but these results did not differ substantively from those presented using the original survey weight. 


\section{Measures}

Our dependent variable was the UCLA Short Loneliness Scale (Hughes, Waite, Hawkley, \& Cacioppo, 2004). Respondents were asked how often they felt "isolated," "lack[ed] companionship," and were "left out." Responses at Wave 1 were 0 = "hardly ever (or never)," 1 = "sometimes," and $2=$ "often." At Wave 2, the bottom category was separated into two response options for "never" or "hardly ever," but for longitudinal consistency, we collapsed these back into a single category (as recommended by Payne, Hedberg, Kozloski, Dale, \& McClintock, 2014). ${ }^{2}$ The scale for each wave had a range of zero to six (0-6) and showed acceptable internal reliability (Wave $1 \alpha=$ .92 , Wave $2 \alpha=.88$ ).

Our main independent variable was self-reported functional limitations. Respondents were asked the degree of difficulty they had performing seven tasks: walking one block, crossing a room, dressing, bathing/showering, eating, getting in and out of bed, and using the toilet. As these are severe impairments, we dichotomized each item $(0=$ "no difficulty" and $1=$ "any difficulty") and then summed them together. We top coded at four or more functional limitations given left skew (range 0-4). We only included Wave 1 functional limitations in our models as previous analyses with these data found changes in functional limitations were not associated with changes in loneliness (Warner \& Adams, 2016). Changes in functional limitations also do not appear to result in across-the-board changes in the quality of social ties - at least among the married (Robles, Slatcher, Trombello, \& McGinn, 2014 ). About $68 \%$ of respondents had the same number of functional limitations at both waves.

SRCs were derived from respondents' assessments of the quality of their relationships with their spouse (if married), with family, and with friends at each wave (Bookwala \& Franks, 2005; Walen \& Lachman, 2000; Warner \& Kelley-Moore, 2012). ${ }^{3}$ We used reports from both waves because social relations are dynamic over time (Macmillan \& Copher, 2005), and thus, there is the potential for change that might affect their ability to serve as coping resources.

Two items assessed respondents' support from each type of relationship: the frequency with which they could (a) "talk about ... worries" with [spouse/ family/friends] and (b) "rely on [spouse/family/friends] if [they] have problems." Two items assessed strain in each type of relationship: the frequency with which respondents' (c) [spouse/family/friends] made "too many demands" and (d) [spouses/family/friends] "criticize[d]" them. Responses were coded $0=$ "hardly ever (or never)," $1=$ "some of the time," and $2=$ "often" (see Note 3). Two additional items referred only to the relationship with a 
spouse. Respondents were asked whether they "spend free time doing things together" with their spouse $(0=$ "different/separate things," $1=$ "some together/some different," and 2 = "together"). Respondents also provided a global assessment of marital happiness. This measure, as is typical, was extremely skewed toward more positive assessments. ${ }^{4}$ Consequently, we collapsed the responses into a reverse coded three-level measure of marital unhappiness, where $0=$ "very happy (7)," $1=$ "happy $(5,6)$," and $2=$ "unhappy $(1,2,3,4)$ " $(r=-.95$ with original measure at Wave $1 ; r=-.96$ with original measure at Wave 2).

As described below, SRCs were constructed using LCA for married and unmarried respondents separately, so measures pertaining to the marital relationship were only included in the LCA for married respondents. For measures about the quality of family or friend relationships, we coded respondents who reported no family or friends as zero on these indicators because, without these ties, they could not experience them. In preliminary analyses, we included two dummy variables for no family and no friends to account for this structural issue. As few people reported having no family, only no friends was retained.

Based on prior research, we included several control variables measured at Wave 1: female; age (centered at 57 years); dummy variables for Black, Hispanic, and Other race (White was the reference); a dummy variable for less than high school education; dummy variables for household income $<$ US\$50k and income missing (income $>$ US\$50k was the reference) ${ }^{5}$; a dummy variable for two or more marriages; and the frequency of religious service attendance $(0=$ "never" to $6=$ "several times a week"). We considered several other controls in preliminary analyses, including respondent's self-rated health, chronic conditions, rating of partner's physical health, and indicators of social integration (i.e., paid work, network size, number of children, number of close relatives, and socializing with neighbors). None of these measures significantly affected our findings (see also Cornwell \& Waite, 2009; Due et al., 1999) and were thus excluded from the final analyses.

\section{Analytic Strategy}

Latent class analysis. As described above, we have 15 different indicators at each wave assessing the positive/supportive and negative/straining aspects of respondents' relationships with a spouse, family, and friends. Following Macmillan and Copher (2005), we used LCA to identify different configurations that summarize the multidimensional nature of social relations among older adults (see also Birditt \& Antonucci, 2007; Miche 
et al., 2013). Given the centrality of marriage for organizing social life, including placing primacy on the spouse and structuring ties to kin and nonkin (Waite \& Lehrer, 2003), we performed the LCA separately for married and unmarried respondents. Although prior research suggests differences in social relations between the never married, divorced, and widowed (Pinquart, 2003; Sarkisian \& Gerstel, 2016), there were too few cases to perform the LCA for these unmarried groups separately. ${ }^{6} \mathrm{We}$ estimated a series of models that specified two to six (2-6) latent classes each for married and unmarried respondents. We identified the best-fitting solution based on a combination of model fit (i.e., Akaike information criterion [AIC], and Bayesian information criterion [BIC]), parsimony, and interpretability (Collins \& Lanza, 2010). ${ }^{7,8}$ We used Latent GOLD 5.1 for the LCA; multiple, software-generated random start value sets were used to protect against local solutions (Vermunt \& Magidson, 2016).

Social relations were best captured with a 5-class solution for married older adults and a 4-class solution for unmarried older adults (see notes 7 and 8). Both solutions had acceptable entropy $R^{2}$ values (.76), an assessment of the precision of assigning latent class membership (range 0-1). We assigned respondents to the SRC with the highest posterior probability of membership $(\gamma)$ and created dummy variables for each; $79.8 \%$ of married and $81.7 \%$ of unmarried respondents were assigned to a latent class with $\gamma \geq 0.70$ (Nagin, 2005).

Tobit regression models. To examine the link between functional limitations, social relations, and loneliness, we used Tobit regression models (Long, 1997) to account for the restricted measurement of the loneliness scale, where $57 \%$ and $52 \%$ of respondents scored zero $(0)$ at Waves 1 and 2 . This approach yields maximum likelihood estimates of the theoretically continuous and normally distributed underlying loneliness construct while accounting for the fact that the observed measure is censored at zero. For cases above zero, Tobit regression uses a standard linear model.

We first estimated two models in the pooled sample (a) to establish the association between functional limitations, SRCs, and changes in loneliness and (b) then specified interaction terms to examine how SRCs moderate the association between functional limitations and changes. We then estimated gender-stratified models, testing the equality of coefficients, to assess whether these associations differed between men and women. We used the regressor variable method (Allison, 1990) to model changes in loneliness, predicting Wave 2 loneliness while controlling for its Wave 1 value. All Tobit analyses were weighted and conducted using SAS ${ }^{\circledR} 9.4$. 


\section{Results}

The means and standard deviations for loneliness, functional limitations, and the control variables are provided in Table 1 . Respondents had relatively low levels of loneliness that increased between Waves 1 and $2(t=3.74, p<.001)$. Respondents had less than one limitation $(M=0.65)$ on average; among the $29.9 \%$ of respondents with limitations, the average number of limitations was 2.27 (not shown). The sample contained about equal numbers of men and women ( $49 \%$ vs. $51 \%$, respectively). Respondents were on average about 68 years old; more than three quarters were White, most had at least a high school education, about half had incomes under US\$50,000 per year, and attended religious services slightly less than "once a month." Women were lonelier at both waves, had more limitations, had lower incomes, and attended religious services more frequently. Men were more likely than women to be married ( $83 \%$ vs. $53 \%$, respectively; $t=12.72, p<.001$; not shown) and to have been married at least twice ( $34 \%$ vs. $26 \%$, respectively; $t=3.08, p=.002$ ). As expected, married respondents were less lonely than unmarried respondents $(0.70$ vs. 1.47 , respectively; $t=9.45, p<.001$, ) and had fewer functional limitations ( 0.56 vs. 0.86 , respectively; $t=3.86, p<.001)$ at Wave 1 (not shown).

\section{Social Role Configurations}

As reported above, older adults' SRCs were best captured with a five-class solution for married older adults and a four-class solution for unmarried older adults. We gave each latent class a descriptive label based on (a) a review of the conditional means and probabilities, which indicate how each latent class is related to each of the indicator variables and (b) comparing a given class' estimated means/probabilities to those of the other classes (Collins \& Lanza, 2010). The conditional means for the Wave 1 indicators are presented in Table 2; the means for the Wave 2 indicators are omitted because the values were relatively stable across waves for all but one class (discussed below) and did not aid in the interpretation. ${ }^{9}$

For married older adults, we labeled the five SRCs: (a) couple-centered high values on positive and low values on negative marital quality, but only modest values on support from family and friends; (b) happy - the highest values on the positive aspects and the lowest values on the negative aspects of relations with spouse, family, and friends; (c) volatile - high values on positive aspects of the marital relationship combined with modest levels on the negative aspects (but very low on unhappiness), with a similar pattern for relations with family and friends; (d) bickering - low levels on the positive 
Table I. Descriptive Statistics for Pooled Sample and by Gender.

\begin{tabular}{|c|c|c|c|c|c|c|c|}
\hline & \multirow[b]{2}{*}{$M$} & \multirow[b]{2}{*}{$S D$} & \multicolumn{2}{|c|}{ Men } & \multicolumn{2}{|c|}{ Women } & \multirow[b]{2}{*}{$t$ test $^{\mathrm{a}}$} \\
\hline & & & $M$ & $S D$ & $M$ & $S D$ & \\
\hline \multicolumn{8}{|l|}{ Loneliness } \\
\hline Loneliness (Wave I) & 0.95 & 1.36 & 0.79 & 1.21 & 1.10 & 1.42 & $4.4 I^{* * * *}$ \\
\hline Loneliness (Wave 2) & 1.08 & $\mathrm{I} .43$ & 0.99 & 1.42 & 1.17 & 1.42 & $2.39 *$ \\
\hline Functional limitations & 0.65 & 1.28 & 0.52 & 1.14 & 0.78 & 1.39 & $3.78 * * *$ \\
\hline Female & 0.51 & & & & & & \\
\hline $\mathrm{Age}^{\mathrm{b}}$ & 67.87 & 7.42 & 67.60 & 7.42 & 68.12 & 7.42 & 1.30 \\
\hline \multicolumn{8}{|l|}{ Race/ethnicityc } \\
\hline White & 0.78 & & 0.79 & & 0.77 & & 0.76 \\
\hline Black & 0.11 & & 0.10 & & 0.12 & & 1.62 \\
\hline Hispanic & 0.08 & & 0.09 & & 0.07 & & 1.13 \\
\hline Other & 0.03 & & 0.03 & & 0.03 & & 0.29 \\
\hline $\begin{array}{l}\text { Less than high school } \\
\text { Income }^{d}\end{array}$ & 0.14 & & 0.13 & & 0.15 & & 1.08 \\
\hline Income < US $\$ 50 \mathrm{k}$ & 0.52 & & 0.45 & & 0.59 & & $5.12 * * *$ \\
\hline Income $\geq U S \$ 50 \mathrm{k}$ & 0.41 & & 0.50 & & 0.32 & & $\mathrm{I} .14^{\dagger}$ \\
\hline Income missing & 0.07 & & 0.05 & & 0.09 & & $2.90 * *$ \\
\hline Married twice or more & 0.30 & & 0.34 & & 0.26 & & $3.08 * *$ \\
\hline $\begin{array}{l}\text { Religious service } \\
\text { attendance }\end{array}$ & 3.84 & 2.06 & 3.24 & 2.11 & 3.72 & 1.98 & $4.3 I^{* * * *}$ \\
\hline$N$ & 1,388 & 680 & 708 & & & & \\
\hline
\end{tabular}

Source. National Social Life, Health, and Aging Project (NSHAP).

Note. Unweighted estimates. SD omitted for dichotomous variables.

aSatterthwaite $t$ test for difference in the means by gender is zero.

bMean-centered in multivariate analyses.

"White" is the reference category in multivariate analyses.

d"Income $\geq U S \$ 50 \mathrm{k}$ " is the reference in multivariate analyses.

$t_{p}<.10 . *_{p}<.05$. $* * p<.01$. ${ }^{* * *} p<.001$ (two-tailed tests).

and very high on the negative aspects of the marital relationship, similarly problematic relationships with family, and very few friendships; and (e) withdrawing - the lowest levels on positive marital quality and the highest levels on negative marital quality, but family and friends appear relatively supportive. This last configuration is the only one where there were differences between waves - with spousal indicators decreasing and support from family and friends increasing over time. Interestingly, these respondents were less unhappy by Wave 2 (perhaps having become indifferent to their spouse, turning to nonmarital relations to meet their support needs). 


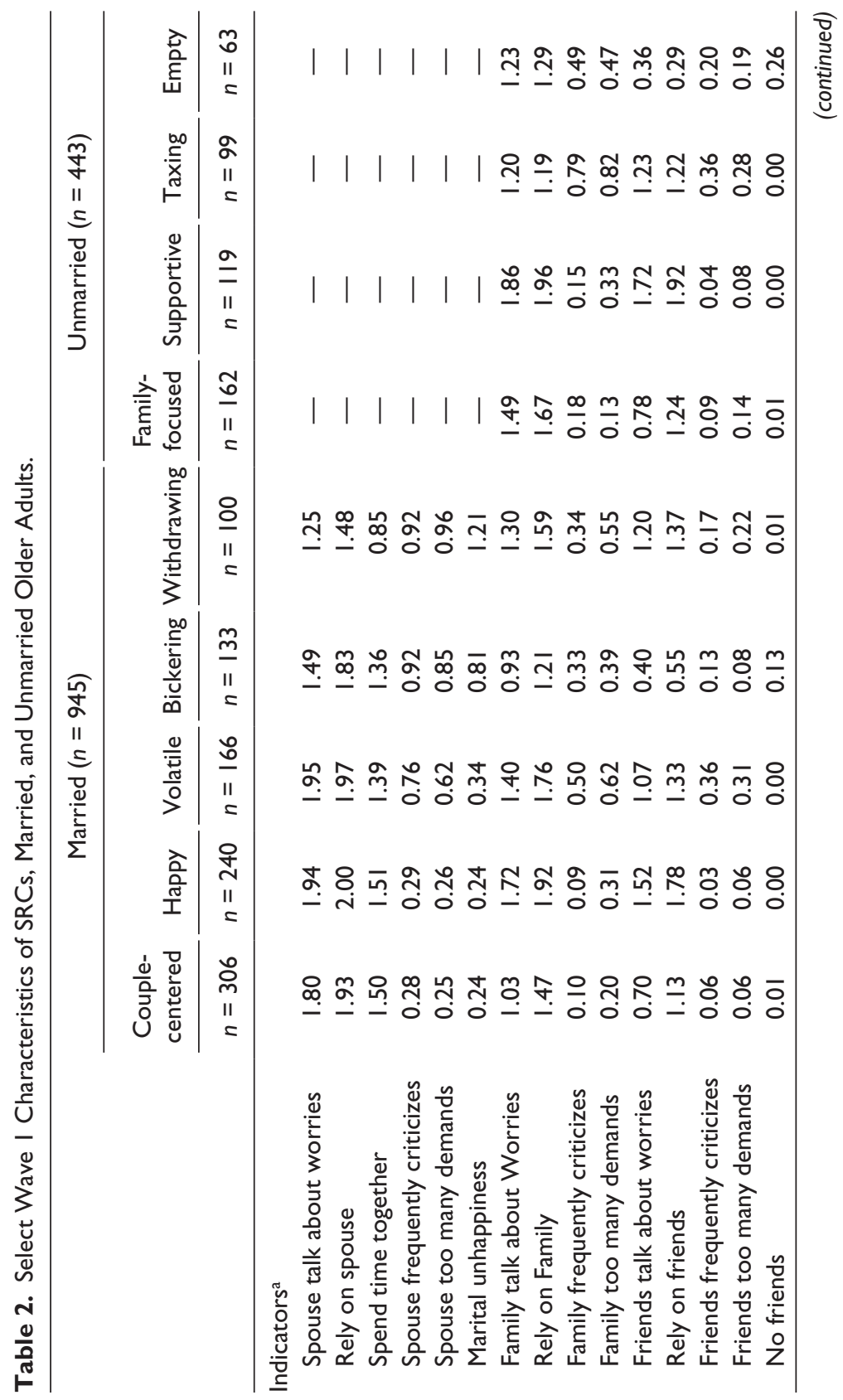




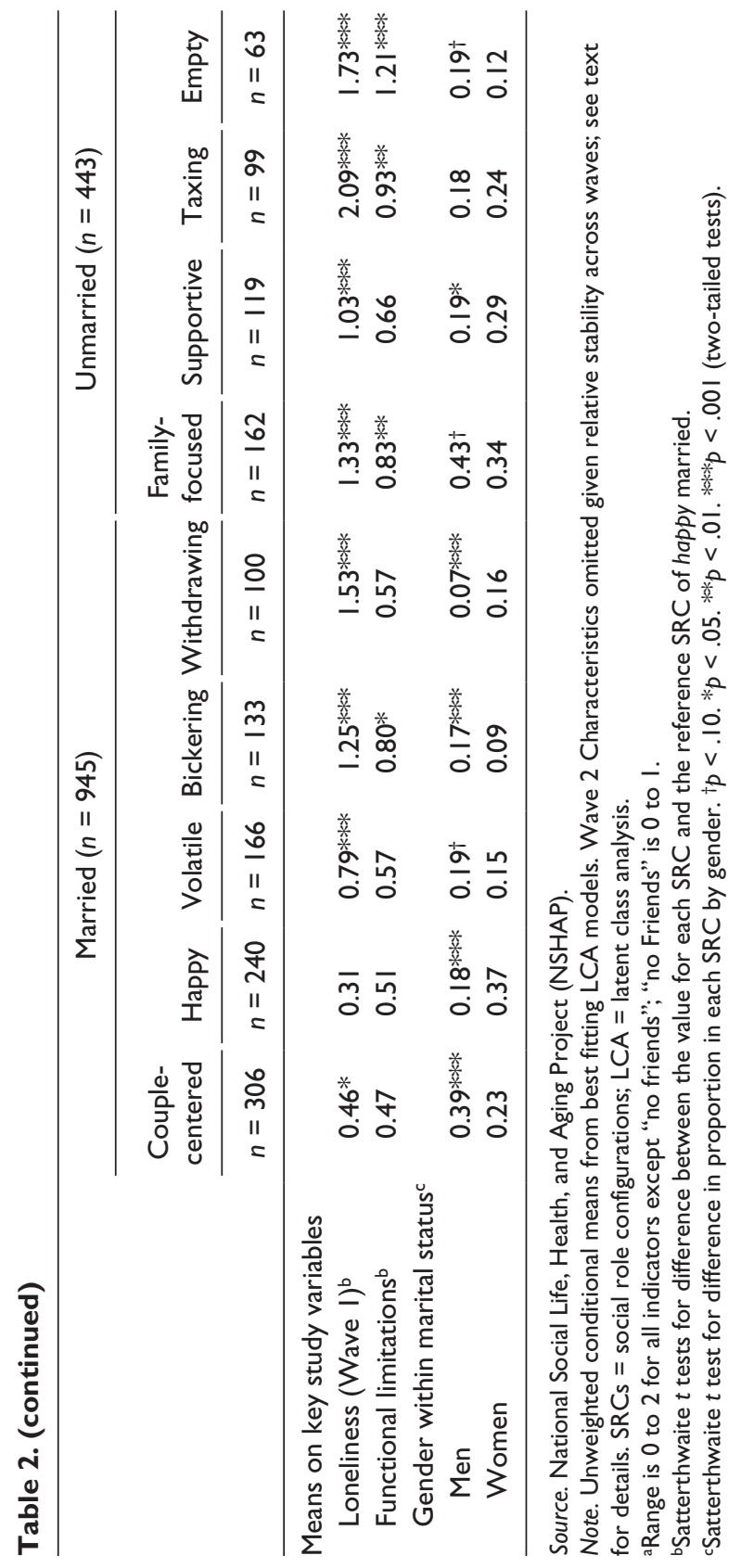


The couple-centered and happy configurations captured more than half of married respondents (32\% and 24\%, respectively) and largely correspond to what are commonly thought of as "good" marriages. Aside from the withdrawing configuration, the identified SRCs showed that the positive and negative characteristics of one relationship (e.g., with a spouse) tend to generalize across others (e.g., with family and with friends; see Akiyama et al., 2003), even as the absolute levels may differ. Respondents classified as couple-centered had relations most consist with the expectation of a hierarchical arrangement.

Married older men and women were not equally likely to be in each of the SRCs. Married men were significantly more likely to have social relations classified as couple-centered $(t=5.39, p<.001)$ or bickering $(t=1.67$, $p=.095$ ). Men were also marginally more likely to be classified as volatile $(t=3.90, p<.001)$. These are the configurations where relations with family and friends are secondary to marriage. By contrast, married women were significantly more likely to be classified as happy $(t=6.41, p<.001)$ or withdrawing $(t=4.85, p<.001)$. These two configurations reflect situations where support from family and friends is high (or increasing) relative to that from a spouse.

The four unmarried SRCs identified were largely analogous to those among the married. We labeled the SRCs: (a) family-focused - high levels of support from family but not friends; (2) supportive-highest levels of support from both family and friends, with very low strain; (3) taxing - modest to low levels of support from family and friends, but very high levels of strain; and (4) empty - modest to low levels of support from family, but low on all other aspects of nonmarital relations (in part due to a rather high percentage reporting that they did not have any friends).

The family-focused and supportive configurations captured more than half of unmarried respondents ( $35 \%$ and $27 \%$, respectively), whereas just $14 \%$ were in the empty class. In contrast to the married, there were fewer clear gender differences in unmarried SRCs. Unmarried men were marginally more likely to have social relations classified as family-focused $(t=1.70, p=.091)$ and empty $(t=1.69, p=.092)$. Unmarried women were significantly more likely to be in the supportive configuration $(t=2.20, p=.029)$. The prevalence of the Taxing configuration did not differ by gender.

Comparing across all nine of the SRCs, the happy married configuration appears to be the most advantaged with respect to protecting against loneliness and coping with physical disability (see Table 2). Indeed, respondents in the happy married SRC had significantly lower mean levels of loneliness at Wave 1 compared with all other SRCs. We note that the happy married configuration is even significantly different from the couple-centered married 
configuration $(t=-2.11, p=.035)$, which is similarly characterized by high positive and low negative marital quality, pointing to the potential added importance of supportive ties beyond one's spouse. There are fewer mean differences across SRCs in functional limitations, especially, among the married configurations. Nevertheless, married respondents classified as happy had significantly fewer functional limitations than did married respondents in the bickering $(t=-2.39, p=.018)$ and unmarried respondents in the family-focused $(t=-2.67, p=.009)$, empty $(t=-2.66, p=.009)$, and taxing $(t=-3.65, p<.001)$ SRCs. Accordingly, the happy married SRC is the reference groups in the analyses that follow.

\section{Tobit Regression Results}

The results for the effect of functional limitations and SRCs on changes in loneliness are presented in Table 3. Consistent with prior studies, functional limitations were associated with increased loneliness at Wave $2(b=0.23$, $p<.001$; Model 1). Relative to married persons in the happy SRC, all of the other SRCs were associated with increased loneliness. The couple-centered married $(b=0.37, p=.062)$ and supportive unmarried $(b=0.50, p=.065)$ SRCs were only marginally different from those in the happy married SRC. For the most part, the other SRCs reflect low positive/supportive and/or high negative/strained social relations (or lacked friends), and thus, increased loneliness is to be expected. It is surprising, however, that unmarried older adults in the family-focused SRC - which is characterized by a notable lack of strain - would be associated with increased loneliness $(b=0.99, p<.001)$. Cross-comparisons (not shown) indicate that most SRCs are statistically different from one another (the couple-centered and supportive do not differ).

Although SRCs were differentially associated with changes in loneliness, the effect of functional limitations does not appear to be exacerbated among older adults with SRCs other than happy marriages - contrary to expectations (Model 2). In fact, each of the interaction terms between functional limitations and the SRC dummies is negative. Among bickering married persons, the effect of functional limitations was marginally lower than would be expected $(b=-0.28, p=.069)$. For withdrawing married persons, the significant negative effect $(b=-0.51, p=.008)$ suggests changes in loneliness were not just lower than otherwise would be expected with functional limitations-but nonexistent, given that it was equal in magnitude to the main effect of functional limitations (which applies to our reference groups of the happy married SRC, $b=0.50, p<.001$; and this effect was significantly different from the other SRCs among married persons; not shown). Each of the unmarried SRCs (which did not differ from one another) experienced a 
Table 3. Effect of Functional Limitations and SRCs on Change in Loneliness, Tobit Regression Estimates $(N=1,388)$.

Model I

Model 2

\begin{tabular}{|c|c|c|}
\hline \multicolumn{3}{|l|}{ Independent variables } \\
\hline Loneliness (Wave I) & $0.80 * * *$ & $0.81 * * *$ \\
\hline Functional limitations & $0.23 * * * *$ & 0.50 **** \\
\hline \multicolumn{3}{|l|}{$S R C s^{a}$} \\
\hline \multicolumn{3}{|l|}{ Married } \\
\hline Couple-centered & $0.37^{\dagger}$ & $0.57 *$ \\
\hline Volatile & $0.82^{* * *}$ & $0.99 * * * *$ \\
\hline Bickering & $0.99 * * *$ & $1.21 * * * *$ \\
\hline Withdrawing & $\left.1.5\right|^{* * * *}$ & $1.81 * * * *$ \\
\hline \multicolumn{3}{|l|}{ Unmarried } \\
\hline Family-focused & $0.99 * * *$ & $1.30 * * * *$ \\
\hline Supportive & $0.50^{\dagger}$ & $0.80 * *$ \\
\hline Taxing & $1.13^{* * * *}$ & $1.22 * * *$ \\
\hline Empty & $1.05^{* *}$ & $1.38 * * * *$ \\
\hline \multicolumn{3}{|l|}{ Interaction terms } \\
\hline \multicolumn{3}{|l|}{ Married } \\
\hline Couple-centered $\times$ functional limitations & - & -0.24 \\
\hline Volatile $\times$ functional limitations & - & -0.23 \\
\hline Bickering $\times$ functional limitations & - & $-0.28^{\dagger}$ \\
\hline Withdrawing $\times$ functional limitations & - & $-0.5 \mathrm{I} * *$ \\
\hline \multicolumn{3}{|l|}{ Unmarried } \\
\hline Family-focused $\times$ functional limitations & - & $-0.44 * *$ \\
\hline Supportive $\times$ functional limitations & - & $-0.5 \mathrm{I} * *$ \\
\hline Taxing $\times$ functional limitations & - & -0.20 \\
\hline Empty $\times$ functional limitations & - & $-0.4 I^{*}$ \\
\hline \multicolumn{3}{|l|}{ Control variables } \\
\hline Female & 0.09 & 0.15 \\
\hline$A g e^{b}$ & $0.02 *$ & $0.02 *$ \\
\hline \multicolumn{3}{|l|}{ Race/ethnicityc } \\
\hline Black & 0.23 & 0.29 \\
\hline Hispanic & $-0.77 * *$ & $-0.78 * *$ \\
\hline Other & 0.03 & 0.02 \\
\hline Less than high school & -0.18 & -0.15 \\
\hline \multicolumn{3}{|l|}{ Income $^{d}$} \\
\hline Income $<$ US $\$ 50 \mathrm{k}$ & 0.13 & 0.14 \\
\hline Income missing & 0.07 & -0.07 \\
\hline Married twice or more & $-0.3 I^{*}$ & $-0.34 * *$ \\
\hline Religious service attendance & $-0.08 * *$ & $-0.08 * *$ \\
\hline Intercept & $-1.35 * * *$ & $-1.59 * * *$ \\
\hline Sigma & 1.97 & 1.97 \\
\hline
\end{tabular}

Source. National Social Life, Health, and Aging Project (NSHAP).

Note. Estimates weighted and variances adjusted for stratification and clustering. SRCs = Social Role

Configurations.

a"Happy" SRC is the reference.

bMean-centered.

c"White" is the reference.

${ }^{d}$ "Income $\geq$ US $\$ 50 \mathrm{k}$ " is the reference. ${ }^{\dagger} p<.10 . *_{p}<.05$. ${ }^{* *} p<.01$. $*^{* *} p<.001$ (two-tailed tests). 
smaller increase in loneliness with functional limitations than would be expected relative to the happy married SRC. Given the substantially higher levels of baseline loneliness among these SRCs (see Table 2), the negative interactions in Model 2 may reflect a ceiling effect. As the next section indicates, however, there were also key gender differences in the implications of different SRCs.

\section{Gender Stratified Results}

Table 4 replicates the previous Tobit regression models separately for men and women, with adjusted Wald tests assessing whether coefficients for men and women are statistically different. Model 1 indicates that functional limitations were associated with increased loneliness for both men $(b=0.35$, $p<.001)$ and women $(b=0.14, p=.014)$, but this effect was greater for men $(p=.034)$. Each of the SRCs was associated with similar increases in loneliness for men and women compared with happy married older adults. Once we specified interactions between SRC and functional limitations, however, a number of gender differences emerged (Model 2).

Examining the main effects of SRC for those without functional limitation in Model 2, we found that men in the bickering $(p=.020)$, withdrawing $(p=.011)$, and taxing $(p=.031)$ configurations saw substantially greater increases in loneliness than women in the same SRC. Each of these configurations is marked by excess negativity: low support and high strain, and, for the married, high marital unhappiness.

Among those with functional limitations, SRCs had opposite effects for men and women. For men, the main effect of functional limitations $(b=0.83$, $p<.001)$ indicates that functional limitations among those in the reference happy married SRC actually predicted increases in loneliness over time. Men with functional limitations in other SRCs, however, did not experience a significant increase in loneliness as the negative interaction terms offset the positive main effects. There are three exceptions to this. First, married men with functional limitations in the withdrawing configuration, which reflects declining marital quality and increases in family and friend support over time, experienced even larger increases in loneliness $(b=0.81, p=.015)$ relative to the happy SRC. Second, unmarried men in the supportive SRC did not differ from men in happy marriages and thus also experience increased loneliness with functional limitations. Third, unmarried men in the taxing SRC also did not significantly differ from the happy married SRC - although we caution that this group is rather small. Overall, it appears that for men in all but the most positive SRCs, their elevated and increasing loneliness means that a stressor, such as functional limitations, appears to have been of little 
Table 4. Effects of Functional Limitations and SRCs on Change in Loneliness by Gender, Tobit Regression Estimates. ${ }^{a}$.

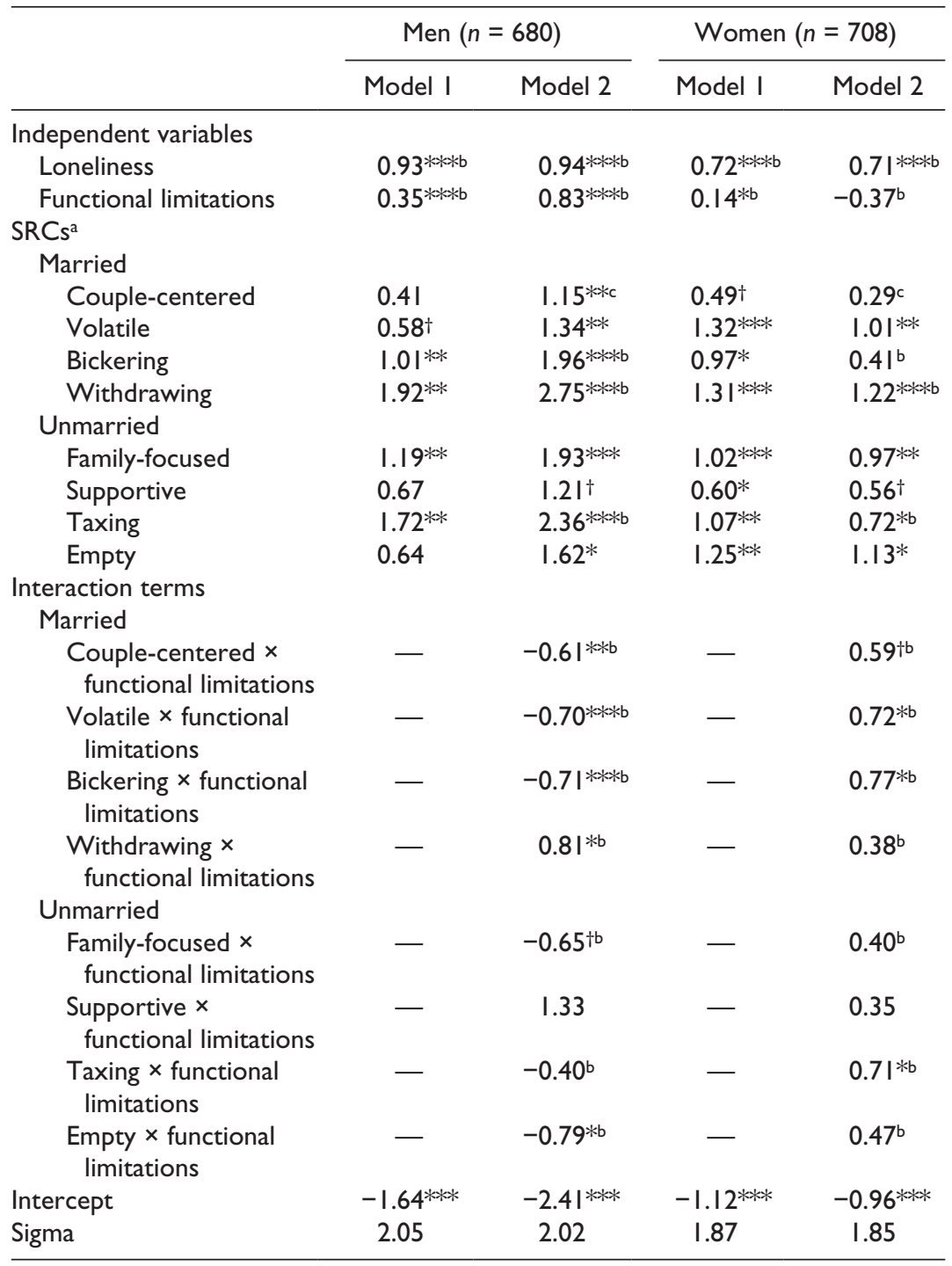

Source. National Social Life, Health, and Aging Project (NSHAP), Waves I and 2.

Note. Estimates weighted and variances adjusted for stratification and clustering. Control variables omitted from the table. SRCs = social role configurations.

a"Happy" SRC is the reference.

${ }^{b}$ Adjusted Wald test for significant difference between men and women, $p<.05$.

cAdjusted Wald test for significant difference between men and women, $p<.10 . t p<.10$.

$*_{p}<.05 . * * p<.01$. $*_{* *} p<.001$ (two-tailed tests). 
consequence. That is, married men in the happy and unmarried men in the supportive SRCs were more vulnerable to stress-inducing effects of functional limitations.

In contrast to men, the effect of functional limitations was not statistically significant for women (difference between men and women, $p<.001$ ). This means married women in the happy SRCs with higher levels of functional limitations did not experience a change in loneliness over time. Less supportive SRCs, however, appear to exacerbate the effects of functional limitations on loneliness for married women.

The positive interaction terms for women in volatile and bickering marriages mean that functional limitations were associated with increased loneliness over time. Women with functional limitations withdrawing from their marriages did not experience an additional increase loneliness, unlike men (difference between men and women, $p=.015$ ).

Women in couple-centered marriages also experienced a marginal increase in loneliness with greater functional limitations $(b=0.59, p=.074$; difference between men and women, $p=.004$ ) even though there was no difference between couple-centered and happy marriages among women without functional limitation. Recall that these marriages involve high positive and low negative marital quality, but only modest support from family and friends. This suggests that the perceived supportive behavior of husbands only somewhat buffers the effect of functional limitations for women in such marriages.

Unmarried women with taxing and empty social relations also experienced increases in loneliness with functional limitations compared with the happy married configuration (and these effects were similar in magnitude and did not significantly differ from one another; not shown). The absence of a significant difference in the effect of functional limitations for unmarried women in the family-focused and supportive SRCs suggests that these configurations of social relations are just as effective as happy marriages at buffering loneliness. Overall, these findings suggest that for older women whose social relations are characterized by a lack of support and excess strain, there exists the potential for functional limitations to act as a stressor.

\section{Discussion and Conclusion}

This study offers new insights into how married and unmarried older adults' combined assessments of the quality of their social relations affect loneliness among those with functional limitations. Using data from two waves of the NSHAP, we examined how the positive/supportive and negative/straining aspects of social relations across the domains of spouse, family, and friends form different configurations that may serve as resources for coping with the 
loneliness-inducing effects of functional limitations. We grounded our assessment of social relations in a family life course perspective (Macmillan \& Copher, 2005). This approach recognizes (a) that each social role is defined by normative expectations and the subjective evaluation of how well the role meets those normative expectations and (b) that multiple social roles operate together. Indeed, we found that older adults' social relations combine in complex ways.

Consistent with prior studies (Birditt \& Antonucci, 2007; Fingerman et al., 2004; Lee \& Szinovacz, 2016), the SRCs we identified make clear that the positive/supportive and negative/straining aspects of relations are separate, independent dimensions for both the married and the unmarried. Moreover, the quality of relationships in one domain (e.g., with a spouse) tend to generalize to other domains (e.g., with family). It is rare that older adults have qualitatively different experiences of support and strain across domains - the withdrawing configuration among the married is an exception to this.

Although older adults' social relations combine into several different configurations, they are all associated with higher levels of loneliness than married older adults whose relationships we characterized as happy - those with the most positive/supportive and least negative/strained relationships across all domains. The couple-centered for the married and the supportive SRCs for the unmarried appear to be at least somewhat effective at preventing further increases in loneliness over time. Married older adults whose SRCs are characterized by greater demands and criticism from spouses and are unhappy in their marriages - regardless of whether or not they have support from family or friends (i.e., bickering or withdrawing SRCs) - are lonelier and experience a greater increase in loneliness over time than unmarried older adults who have positive relations with family and friends (i.e., supportive and family-focused SRCs). These patterns hold for both men and women although SRCs characterized by negativity/strain have somewhat stronger effects on loneliness for men. This differs from prior research that has suggested that women exhibit greater physiological response to negativity in social relations (e.g., Robles et al., 2014), suggesting that gender differences in the consequences of social relations depend on the outcome being examined.

We find that the consequences of social relations for older adults' ability to cope with physical disability are highly gendered, and this is true for not only the married (Warner \& Adams, 2016) but also for the unmarried. Women are somewhat buffered from the increased loneliness that accompanies disablement if they have social relations that are characterized by positive/supportive behaviors from the expected primary relationship; for married women this means happy and couple-centered SRCs and for unmarried women it 
means supportive and family-focused SRCs. Among both married and unmarried older adults, SRCs characterized by low levels of positive/supportive behaviors and/or high levels of negative/straining behaviors are associated with greater baseline loneliness. However, for women with functional limitations, such excess negativity compounds over time lead to increased loneliness.

For men, SRCs characterized by excess negativity/strain do not appear to exacerbate the consequences of functional limitations - perhaps because these men are already quite lonely. Rather, it is married men in happy marriages or unmarried men with supportive relations - those that have very high levels of positive and the lowest levels of negative behaviors across domains - who appear to be at risk of increasing loneliness over time with functional limitations. Prior research suggests that increases in ostensibly negative behaviors - especially demands - in response to health challenges can help mitigate their consequences for married men (a form of "beneficial negativity"; see Birditt \& Antonucci, 2008; Warner \& Adams, 2016). It appears that a similar process may occur for unmarried men. The greater vulnerability of married men in the happy SRC and unmarried men in the supportive SRC to stress-inducing effects of functional limitations are also consistent with prior work showing that excessive support may have harmful effects when it is overly solicitous (e.g., Reinhardt et al., 2006). The findings here suggest that for both married and unmarried men with functional limitations, a little bit of "strain" in their social relations can actually be a good thing (as long as it is accompanied by support). However, sustained negative/ straining behaviors over time have detrimental effects (Neff \& Karney, 2005). Indeed, we find that older adults with SRCs characterized by high levels of such behaviors - even when they co-occur with support-have higher levels of baseline loneliness and greater increases over time (e.g., volatile, bickering, and taxing SRCs).

Physicians, social workers, and others who work with older adults should recognize that both the positive/supportive and negative/straining aspects of social relations matter. Such professionals would do well to counsel spouses and family that making a few demands of older men with functional limitations is actually beneficial, whereas older women with functional limitations would benefit most from their primary relationship offering greater supportive (and fewer demanding) behaviors. Given that loneliness predicts declines in self-rated health, worsening cognitive abilities, health services use (Cacioppo et al., 2003), and even mortality (Holt-Lunstad et al., 2015), clinicians' understanding of the complex and gendered ways that social relations affect loneliness among older adults with functional limitations is important. 
Our study is among the first to examine how different SRCs - defined by both the presence and quality of social relations across multiple domainsbuffer or exacerbate the loneliness-inducing effects of functional limitations among both married and unmarried older adults. As with all studies, there are several limitations that need to be addressed in subsequent research. First, given the limited sample size, some of the SRCs contained a rather small number of respondents, and thus, some of our statistical tests were underpowered. Our limited sample size, combined with the fact that NSHAP is a community-dwelling sample of persons aged 57 to 85 years at baseline, also prevented us from modeling changes in functional limitations (see also Warner \& Adams, 2016) and whether their consequences for loneliness might depend on SRCs. Studies that include institutionalized persons may be more apt to observe changes in functional limitations.

Second, we were unable to differentiate among unmarried older adults (see note 6). Thus, our results for unmarried older adults largely reflect the experiences of the formerly married. Yet, there are important differences in social relations across unmarried persons. For example, support from family is lower among the divorced - but not among the widowed - compared with the married (Choi, 1996; Cutrona, 1996; Keith, Kim, \& Schafer, 2000). Never married older adults tend to draw more support from friends rather than family (Choi, 1996; Curran et al., 2003). Additional research that permits separate specification of social relation combinations across unmarried groups is needed.

Third, although superior to other nationally representative data, there are relatively few longitudinally assessed indicators of relationship quality in NSHAP. This challenged our interpretations as we could not differentiate elevated levels of demands and criticism that reflect concern from those that reflect conflict. Additional indicators - such as whether spouse/family/ friends get on one's "nerves"-were added to the panel in Wave 2, but the lack of longitudinal measurement precluded their inclusion here.

Finally, we did not have direct information on the quality of older adults' relations with their children or siblings as these were subsumed under "family." Given strong norms of obligations between parents and adult children (Plickert et al., 2007; Sarkisian \& Gerstel, 2016), children rank behind only spouses in the hierarchy of social relations for married and unmarried older parents (Chen \& Feeley, 2014). Obligations between siblings are important for unmarried older adults (Connidis \& Davies, 1992; Pinquart, 2003). The lack of specificity clouds our ability to understand the meaning behind assessments of "family" relationships more broadly.

Despite these limitations, these results advance our understanding of the importance of social relations for loneliness among older adults with 
functional limitations and the ways these processes are similar and different for married and unmarried persons. Although married older adults are generally less lonely than unmarried older adults (Russell, 2009), the quality of social relations and how they combine across different relationships matters (Hawkins \& Booth, 2005; Stokes \& Moorman, 2017). For both married and unmarried older adults, in general, social relations characterized by a lack of support and/or an abundance of negative interactions are associated with higher baseline levels of and increases in loneliness over time. This is especially the case for those older adults whose expected primary relationship is deficient and overly negative.

For older adults with functional limitations, the combination of one's social relations matter for changes in loneliness over time; however, the effects differ for men and women. Social role configurations marked by negative social relations with spouses, family, and friends do not appear to exacerbate the consequences of functional limitations for older men. Rather, men whose social relations are on the surface quite good actually experienced increases in loneliness over time. The loneliness effects of functional limitations are exacerbated, however, for older women whose social relations are more strained. Overall, our findings are consistent with the body of literature showing that marriage anchors social resources for many and - provided it is marked by high levels of positive marital quality and low levels of negative marital quality - is associated with lower levels of loneliness. However, we also show that when confronted with a stressor such as functional limitations, supportive (and not overly straining) relations among the unmarried look to be "just as good" as being in a supportive marriage for buffering stress despite their higher initial levels of loneliness.

\section{Authors' Note}

An earlier version was presented at the 69th Annual Meeting of the Gerontological Society of America, November 16 to 20, 2016, New Orleans, LA.

Raeda K. Anderson is now affilaited to Georgia State University, GA, USA

\section{Declaration of Conflicting Interests}

The authors declared no potential conflicts of interest with respect to the research, authorship, and/or publication of this article.

\section{Funding}

The authors disclosed receipt of the following financial support for the research, authorship, and/or publication of this article: This research was supported in part by the Center for Family and Demographic Research, Bowling Green State University, 
which has core funding from the Eunice Kennedy Shriver National Institute of Child Health and Human Development (P2CHD050959). NSHAP is supported by the National Institute on Aging (R01AG021487, R01AG033903, R37AG030481), and by NORC, which was responsible for the data collection. No direct support was received for this article. The opinions expressed herein are those of the authors.

\section{Notes}

1. Although spouses are obviously considered family in the broadest sense, throughout the text, we distinguish between spouses and other kin. We reserve the term "family" for the latter group.

2. The response category options between Waves 1 and 2 for several frequency items - including loneliness and relationship qualities - changed, with the lowest category of "hardly ever (or never)" split into two separate groups. For longitudinal assessments of change, items need to be consistently measured. This is why the NSHAP investigators recommend collapsing the Wave 2 response categories "never" and "hardly ever" into a single category so that the measures are identical to those in Wave 1 (Payne, Hedberg, Kozloski, Dale, \& McClintock, 2014).

3. Although the items for the marital relationship refer to a specific person, the items for family and friends are evaluations of these relations collectively (see also Lee \& Szinovacz, 2016).

4. More than half of respondents at each wave rated their marriage a 7 ("very happy"), whereas only about $10 \%$ indicated their marriage was a 4 or lower (Wave 1 skewness $=-1.75$, Wave 2 skewness $=-2.63$ ).

5. In preliminary analyses, we included household assets rather than income, but the results did not substantively differ, and thus, we used income due to lower item-nonresponse.

6. Our unmarried sample was $58 \%$ widowed $(n=255), 33 \%$ divorced $(n=148)$, and just $9 \%$ never married $(n=40)$.

7. Among married respondents, the Bayesian information criterion (BIC) and Akaike information criterion (AIC) showed model improvement for the fiveclass solution $(\mathrm{BIC}=38,077.589$ and $\mathrm{AIC}=37,194.288)$ in comparison with the four-class solution $(\mathrm{BIC}=38,148.144$ and $\mathrm{AIC}=37,415.296)$. In comparisons between the five-class versus six-class solution, there was a slight increase in the $\mathrm{BIC}$ for the six-class solution $(\mathrm{BIC}=38,109.565$ and $\mathrm{AIC}=37,075.812)$.

8. Among unmarried respondents, the BIC and AIC showed model improvement for the four-class solution $(\mathrm{BIC}=10,814.593$ and $\mathrm{AIC}=10,441.464)$ in comparison with the three-class solution $(\mathrm{BIC}=10,846.416$ and $\mathrm{AIC}=10,551.193)$. In comparisons between the four-class versus five-class solution, there was a slight increase in the BIC for the five-class solution $(\mathrm{BIC}=10,818.006$ and $\mathrm{AIC}=10,366.971)$.

9. Stability does not mean, however, that within classes indicators had identical means across waves. As observed in other studies (e.g., Akiyama, Antonucci, Takahashi, \& Langfahl, 2003; Carstensen, Fung, \& Charles, 2003; Due, Holstein, Lund, Modvig, \& Avlund, 1999), the negative aspects of social relations slightly declined even as their relative ranking across classes remained the same. 


\section{ORCID iD}

David F. Warner (iD) https://orcid.org/0000-0002-8658-2237

\section{References}

Akiyama, H., Antonucci, T., Takahashi, K., \& Langfahl, E. S. (2003). Negative interactions in close relationships across the life span. The Journals of Gerontology, Series B: Psychological Sciences \& Social Sciences, 58(2), P70-P79.

Allison, P. D. (1990). Change scores as dependent variables in regression analysis. Sociological Methodology, 20, 93-114.

Antonucci, T. C., \& Akiyama, H. (1987). An examination of sex differences in social support among older men and women. Sex Roles, 17, 737-749.

Antonucci, T. C., Fiori, K. L., Birditt, K., \& Jackey, L. M. H. (2010). Convoys of social relations: Integrating life-span and life-course perspectives. In R. M. Lerner, M. E. Lamb, \& A. M. Freund (Eds.), The handbook of life-span development (Vol. 2, pp. 434-473). Hoboken, NJ: John Wiley.

Barrett, A. E. (1999). Social support and life satisfaction among the never married: Examining the effects of age. Research on Aging, 21, 46-72.

Bernard, J. S. (1972). The future of marriage. New York, NY: World Publishing.

Birditt, K. S., \& Antonucci, T. C. (2007). Relationship quality profiles and well-being among married adults. Journal of Family Psychology, 21, 595-604.

Birditt, K. S., \& Antonucci, T. C. (2008). Life sustaining irritations? Relationship quality and mortality in the context of chronic illness. Social Science \& Medicine, 67, 1291-1299.

Bookwala, J., \& Franks, M. M. (2005). Moderating role of marital quality in older adults' depressed affect: Beyond the main-effects model. The Journals of Gerontology, Series B: Psychological Sciences \& Social Sciences, 60(6), P338-P341.

Burman, B., \& Margolin, G. (1992). Analysis of the association between marital relationships and health problems: An interactional perspective. Psychological Bulletin, 112, 39-63.

Cacioppo, J. T., Hawkley, L. C., \& Berntson, G. G. (2003). The anatomy of loneliness. Current Directions in Psychological Science, 12(3), 71-74.

Carstensen, L. L., Fung, H. H., \& Charles, S. T. (2003). Socioemotional selectivity theory and the regulation of emotion in the second half of life. Motivation and Emotion, 27, 103-123.

Chen, Y., \& Feeley, T. H. (2014). Social support, social strain, loneliness, and wellbeing among older adults: An analysis of the Health and Retirement Study. Journal of Social and Personal Relationships, 31, 141-161.

Choi, N. G. (1996). The never-married and divorced elderly. Journal of Gerontological Social Work, 26(1-2), 3-25.

Collins, L. M., \& Lanza, S. T. (2010). Latent class analysis and latent transition analysis. Hoboken, NJ: John Wiley.

Connidis, I. A., \& Davies, L. (1992). Confidants and companions: Choices in later life. The Journal of Gerontology, 47(3), S115-S122. 
Cornwell, E. Y., \& Waite, L. J. (2009). Social disconnectedness, perceived isolation, and health among older adults. Journal of Health and Social Behavior, 50, 31-48.

Curran, S. R., McLanahan, S., \& Knab, J. (2003). Does remarriage expand perceptions of kinship support among the elderly? Social Science Research, 32, 171190.

Cutrona, C. E. (1996). Social support in couples: Marriage as a resource in times of stress. Thousand Oaks, CA: SAGE.

Due, P., Holstein, B., Lund, R., Modvig, J., \& Avlund, K. (1999). Social relations: Network, support and relational strain. Social Science \& Medicine, 48, 661-673.

Fingerman, K. L., Hay, E. L., \& Birditt, K. S. (2004). The best of ties, the worst of ties: Close, problematic, and ambivalent social relationships. Journal of Marriage and Family, 66, 792-808.

Ha, J.-H. (2008). Changes in support from confidants, children, and friends following widowhood. Journal of Marriage and Family, 70, 306-318.

Hawkins, D. N., \& Booth, A. (2005). Unhappily ever after: Effects of long-term, lowquality marriages on well-being. Social Forces, 84, 451-471.

Hawkley, L. C., \& Kocherginsky, M. (2018). Transitions in loneliness among older adults: A 5-year follow-up in the National Social Life, Health, and Aging Project. Research on Aging, 40, 365-387.

Hawkley, L. C., Kocherginsky, M., Wong, J., Kim, J., \& Cagney, K. A. (2014). Missing data in Wave 2 of NSHAP: Prevalence, predictors, and recommended treatment. The Journals of Gerontology, Series B: Psychological Sciences \& Social Sciences, 69(Suppl. 2), S38-S50.

Holt-Lunstad, J., Smith, T. B., Baker, M., Harris, T., \& Stephenson, D. (2015). Loneliness and social isolation as risk factors for mortality: A meta-analytic review. Perspectives on Psychological Science, 10, 227-237.

Hughes, M. E., \& Waite, L. J. (2009). Marital biography and health at mid-life. Journal of Health and Social Behavior, 50, 344-358.

Hughes, M. E., Waite, L. J., Hawkley, L. C., \& Cacioppo, J. T. (2004). A short scale for measuring loneliness in large surveys. Research on Aging, 26, 655-672.

Johnson, C. L. (1983). Dyadic family relations and social support1. The Gerontologist, 23, 377-383.

Kail, B. L. (2015). Marital status as a moderating factor in the process of disablement. Journal of Aging and Health, 28, 139-164.

Kalmijn, M. (2003). Shared network friendships and the life course: An analysis of survey data on married and cohabitating couples. Social Networks, 25, 231-249.

Kalmijn, M. (2012). Longitudinal analyses of the effects of age, marriage, and parenthood on social contacts and support. Advances in Life Course Research, 17, 177-190.

Keith, P. M., Kim, S., \& Schafer, R. B. (2000). Informal ties of the unmarried in middle and later life: Who has them and who does not? Sociological Spectrum, 20, 221-238.

Korporaal, M., van Groenou, M. I. B., \& van Tilburg, T. G. (2008). Effects of own and spousal disability on loneliness among older adults. Journal of Aging and Health, 20, 306-325. 
Lee, H. J., \& Szinovacz, M. E. (2016). Positive, negative, and ambivalent interactions with family and friends: Associations with well-being. Journal of Marriage and Family, 78, 660-679.

Liebler, C. A., \& Sandefur, G. D. (2002). Gender differences in the exchange of social support with friends, neighbors, and co-workers at midlife. Social Science Research, 31, 364-391.

Lin, I.-F., \& Brown, S. L. (2012). Unmarried boomers confront old age: A national portrait. The Gerontologist, 52, 153-165.

Long, J. S. (1997). Regression models for categorical and limited dependent variables. Thousand Oaks, CA: SAGE.

Macmillan, R., \& Copher, R. (2005). Families in the life course: Interdependency of roles, role configurations, and pathways. Journal of Marriage and Family, 67, 858-879.

Mancini, A. D., \& Bonanno, G. A. (2006). Marital closeness, functional disability, and adjustment in late life. Psychology and Aging, 21, 600-610.

Merz, E.-M., Schuengel, C., \& Schulze, H.-J. (2009). Intergenerational relations across 4 years: Well-being is affected by quality, not by support exchange. The Gerontologist, 49, 536-548.

Miche, M., Huxhold, O., \& Stevens, N. L. (2013). A latent class analysis of friendship network types and their predictors in the second half of life. The Journals of Gerontology, Series B: Psychological Sciences \& Social Sciences, 68, 644-652.

Nagin, D. (2005). Group-based modeling of development over the life course. Cambridge, MA: Harvard University Press.

Neff, L. A., \& Karney, B. R. (2005). Gender differences in social support: A question of skill or responsiveness? Journal of Personality and Social Psychology, 88, $79-90$.

Nock, S. L. (1998). Marriage in men's lives. New York, NY: Oxford University Press.

Payne, C., Hedberg, E. C., Kozloski, M., Dale, W., \& McClintock, M. K. (2014). Using and interpreting mental health measures in the National Social Life, Health, and Aging Project. The Journals of Gerontology, Series B: Psychological Sciences \& Social Sciences, 69(Suppl. 2), S99-S116.

Pearlin, L. I., \& Bierman, A. (2013). Current issues and future directions in research into the stress process. In C. S. Aneshensel, J. C. Phelan, \& A. Bierman (Eds.), Handbook of the sociology of mental health (pp. 325-340). Dordrecht, The Netherlands: Springer.

Pinquart, M. (2003). Loneliness in married, widowed, divorced, and never-married older adults. Journal of Social and Personal Relationships, 20, 31-53.

Pinquart, M., \& Sorensen, S. (2001). Gender differences in self-concept and psychological well-being in old age: A meta-analysis. The Journals of Gerontology, Series B: Psychological Sciences \& Social Sciences, 56, 195-214.

Plickert, G., Côté, R. R., \& Wellman, B. (2007). It's not who you know, it's how you know them: Who exchanges what with whom? Social Networks, 29, 405-429.

Reinhardt, J. P., Boerner, K., \& Horowitz, A. (2006). Good to have but not to use: Differential impact of perceived and received support on well-being. Journal of Social and Personal Relationships, 23, 117-129. 
Robles, T. F., Slatcher, R. B., Trombello, J. M., \& McGinn, M. M. (2014). Marital quality and health: A meta-analytic review. Psychological Bulletin, 140, 140187.

Russell, D. (2009). Living arrangements, social integration, and loneliness in later life: The case of physical disability. Journal of Health and Social Behavior, 50, $460-475$.

Ryan, L. H., Wan, W. H., \& Smith, J. (2014). Spousal social support and strain: Impacts on health in older couples. Journal of Behavioral Medicine, 37, 11081117.

Salari, S., \& Zhang, W. (2006). Kin keepers and good providers: Influence of gender socialization on well-being among USA birth cohorts. Aging and Mental Health, 10, 485-496.

Sarkisian, N., \& Gerstel, N. (2016). Does singlehood isolate or integrate? Examining the link between marital status and ties to kin, friends, and neighbors. Journal of Social and Personal Relationships, 33, 361-384.

Shanas, E. (1979). The family as a social support system in old age. The Gerontologist, 19, 169-174.

Silverstein, M., \& Bengtson, V. L. (1997). Intergenerational solidarity and the structure of adult child-parent relationships in American families. American Journal of Sociology, 103, 429-460.

Silverstein, M., Chen, X., \& Heller, K. (1996). Too much of a good thing? Intergenerational social support and the psychological well-being of older parents. Journal of Marriage and Family, 58, 970-982.

Spitze, G. D., \& Ward, R. (2000). Gender, marriage, and expectations for personal care. Research on Aging, 22, 451-469.

Stokes, J. E., \& Moorman, S. M. (2017). Influence of the social network on married and unmarried older adults' mental health. The Gerontologist. Advance online publication. doi:10.1093/geront/gnx151

Thoits, P. A. (1995). Stress, coping, and social support processes: Where are we? What next? Journal of Health and Social Behavior, 35, 53-79.

Vermunt, J. K., \& Magidson, J. (2016). Upgrade manual for latent GOLD 5.1. Belmont, MA: Statistical Innovations.

Waite, L. J., Cagney, K. A., Dale, W., Huang, E., Laumann, E. O., McClintock, M. K., . . . Cornwell, B. (2014). National Social Life, Health, and Aging Project (NSHAP): Wave 2 and partner data collection [Computer file: ICPSR34921-V1]. Ann Arbor, MI: Inter-University Consortium for Political and Social Research.

Waite, L. J., \& Harrison, S. C. (1992). Keeping in touch: How women in mid-life allocate social contacts among kith and kin. Social Forces, 70, 637-654.

Waite, L. J., \& Lehrer, E. L. (2003). The benefits from marriage and religion in the United States: A comparative analysis. Population and Development Review, 29, 255-275.

Walen, H. R., \& Lachman, M. E. (2000). Social support and strain from partner, family, and friends: Costs and benefits for men and women in adulthood. Journal of Social and Personal Relationships, 17, 5-30. 
Warner, D. F., \& Adams, S. A. (2012). Widening the social context of disablement among married older adults: Considering the role of nonmarital relationships for loneliness. Social Science Research, 41, 1529-1545.

Warner, D. F., \& Adams, S. A. (2016). Physical disability and increased loneliness among married older adults: The role of changing social relations. Society and Mental Health, 6, 106-128.

Warner, D. F., \& Kelley-Moore, J. A. (2012). The social context of disablement among older adults: Does marital quality matter for loneliness? Journal of Health and Social Behavior, 53, 50-66. 